\title{
PENSAR A EXPERIÊNCIA LITERÁRIA A PARTIR DA "VIRADA ONTOLÓGICA”: FICÇÃO, ANTROPOLOGIA, METAFÍSICA
}

\author{
THINKING ABOUT THE LITERARY EXPERIENCE FROM THE \\ “ONTOLOGICAL TURN": FICTION, ANTHROPOLOGY, \\ METAPHYSICS
}

Luiz Guilherme Fonseca (PUC-Rio)

luizguilherme.fonseca@gmail.com

\begin{abstract}
RESUMO: Pelo menos desde a década de 1990 vem ocorrendo a partir da antropologia o que ficou conhecido como "virada ontológica". Influenciada pelo "perspectivismo ameríndio", entre outros trabalhos, essa virada põe em cena justamente aquilo que toda ficção tensiona: os limites de nosso mundo, a consistência de mundos outros e a possibilidade de travessia para eles. $O$ objetivo deste artigo é investigar as contribuições que a chamada "virada ontológica" pode trazer não só para o conceito de ficção, como também para a compreensão da experiência literária. Dessa forma, primeiro faremos um breve levantamento acerca do conceito de ficção e das aproximações recentemente feitas entre ficção, antropologia e metafísica. Depois, traçaremos as bases da "virada ontológica". Por último, com a ajuda do conceito de "expresso transumwéltico" proposto pelo filósofo argentino Gabriel Catren, esboçaremos uma abordagem teórica que leve em conta o emaranhado entre ficção, antropologia e metafísica.
\end{abstract}

PALAVRAS-CHAVE: conceito de ficção; experiência literária; virada ontológica; literatura e antropologia.

\begin{abstract}
At least since the 1990s, based on anthropology, what became known as the "ontological turn" has been taking place. Influenced by "Amerindian perspectivism", among other works, this turn brings into play precisely what all fiction emphasizes: the limits of our world, the consistency of other worlds and the possibility of crossing them. The aim of this article is to investigate the contributions that the so-called "ontological turn" can bring not only to the concept of fiction, but also to the understanding of literary experience. Thus, first we will briefly survey this concept and recent approaches to anthropology and metaphysics. Afterwards, we will trace the bases of the "ontological turn". Finally, with the help of the concept of "trans-umweltic express" proposed by the Argentine philosopher Gabriel Catren,
\end{abstract}


we will outline a theoretical approach that takes into account the entanglement between fiction, anthropology and metaphysics.

KEYWORDS: fiction concept; literary experience; ontological turn; literature and anthropology.

Os metafísicos de Tlön não buscam a verdade nem sequer a verossimilhança: buscam o assombro. Julgam que a metafísica é um ramo da literatura fantástica.

$J$ L Borges, Ficções.

\section{Introdução: dos efeitos da escrita}

É conhecida a descrição que Górgias faz das potências do discurso em seu Elogio de Helena. Exposto, na tradução feita pela filóloga e filósofa francesa Barbara Cassin (2005), como um senhor capaz de "dar fim ao medo, afastar a dor, produzir a alegria, aumentar a piedade", o discurso aparece como uma das causas mais poderosas da variação dos estados afetivos (CASSIN, 2005, p. 297). Barbara Cassin faz questão de ressaltar, em uma das notas da sua tradução, que contrariamente ao que aparece em algumas traduções francesas, na fala de Górgias o discurso não seria um instrumento utilizado pelos deuses, mas antes um deus ele mesmo: "O discurso é, de preferência, um deus, na equação que se forma entre sua pouca materialidade (os sons são tão inapreensíveis quanto os átomos) e seu imenso poder" (CASSIN, p. 297). Seria a partir de seu poderio sobre a variação afetiva, inclusive, que o discurso teria características farmacêuticas, agindo ora como veneno, ora como remédio.

Ainda sobre o caráter divino do discurso, no artigo "Sofística, performance e performativo" (2016), Cassin vai apontar para o seu efeito duplo: não apenas ativando a mudança de estado afetivo no receptor, como também configurando mundos possíveis:

é um efeito sobre a alma, que passa de um estranho para um próprio, somente com palavras; mas é também e ao mesmo tempo um efeito-mundo, em que o objeto do discurso, a "ficção", ganha consistência e se torna realidade (CASSIN, 2016, p. 38).

É claro que não é todo discurso que seria capaz de acionar estados afetivos ou ganhar consistência na realidade. O helenista Marcel Detienne, em seu clássico Os mestres da verdade na Grécia Arcaica, debruçando-se sobre a eficácia das palavras, traça a distinção, no mundo arcaico grego, entre palavras "realizadoras" e palavras "sem realização". As palavras 
"realizadoras", como o nome sugere, são aquelas que efetuam algo no mundo - como o discurso do rei de justiça, um dos mestres da verdade analisados por Detienne. Já as palavras "sem realização" são como "procedimentos adivinhatórios ineficazes, maldições "que caem sobre a terra e não são cumpridas"” (DETIENNE, 1988, p. 35-36).

Eduardo Sterzi, em seu texto "Hipóteses", afirma: "Escreve-se para produzir efeitos. Uma ética da escrita começa por perguntar: quais serão os efeitos do que estou escrevendo?" (2019, p. 250, grifado no original). Mas como se daria a eficácia do discurso, isto é, como o discurso produz efeitos? Uma resposta possível está numa das hipóteses levantadas pelo próprio Sterzi: “Todo signo é paixão paralisada. Uma semiótica viva deve conter, por isso, uma componente clínica, ou mesmo terapêutica, capaz de romper, ainda que momentaneamente, com aquela paralisia" (2019, p. 249). Uma "semiótica viva", dessa forma, deveria ser capaz de acionar potências não vistas, disparando uma ação, alavancando uma mudança: a palavra como feitiço. Em Cosmopoéticas do refúgio, Dénètem Touam Bona nos lembra que a Revolução Haitiana, a revolução anticolonial que instaurou, em 1804, a primeira República Negra, se iniciou com um feitiço. O feitiço conjurado em Bois-Caïman, o feitiço executado pelo cocheiro Dutty Zamba Boukman, o homem do livro, o homem da disseminação da mensagem, foi o disparador da revolução (Cf. TOUAM BONA, 2020, p. 34).

É esse "efeito-mundo" do discurso de que fala Barbara Cassin que nos interessa tratar aqui. "Efeito-mundo" criado a partir das palavras encantadas - e toda palavra que desencadeia uma mudança nos estados afetivos é encantada, das fake news aos discursos do Estado, das rodas de oração às palavras de ordem, e tantas outras. Sem entrar nos debates filosóficos relacionados à sofística, que, segundo Cassin, faz a passagem da ontologia à "logologia", isto é, o ser como "efeito do dizer" (Cf. CASSIN, 2016, p. 35), mas aproveitando essa intuição sobre as palavras eficazes, o que pretendemos nesse artigo é pensar a experiência literária a partir das contribuições que a chamada "virada ontológica" pode trazer ao conceito de ficção. Se uma palavra eficaz, uma ficção, como disse Cassin, pode criar um "efeito-mundo", seria importante pensar isso também a partir das disciplinas que abordam outros mundos e as condições em que uma transição (ou, ao menos, intersecção) entre mundos é possível. Dessa forma, nesse artigo iremos analisar, num primeiro momento, as relações entre ficção, antropologia e metafísica, assim como sua acentuada convergência recente; depois, vamos traçar as bases da chamada "virada ontológica" e suas possíveis consequências para o conceito de ficção; e, por último, iremos pensar, com a ajuda do conceito de "expresso 
transumwéltico" proposto pelo filósofo argentino Gabriel Catren, uma abordagem teórica que leve em conta o emaranhado entre ficção, antropologia e metafísica.

\section{A comparação de mundos (ficção, antropologia, metafísica)}

Os pontos de contato entre ficção, antropologia e metafísica são vastos: desde o possível liame entre pensamento mítico e linguagem $^{1}$, que estaria na base de toda sociogênese, passando pelas relações entre o mito e a ficção, que se encontram também na origem da literatura ${ }^{2}$, até as mais recentes aproximações feitas tanto por escritores quanto por antropólogos e filósofos ${ }^{3}$.

As consequências dessa imbricação entre mitologia e linguagem ficam ainda mais evidentes quando vemos a importância da palavra, oral ou escrita, para a organização cosmológica das sociedades. Seja na metafísica cristã ("no princípio era o verbo") ou na cosmogonia yanomami (as palavras de Omana, o canto dos xapiri) (cf. KOPENAWA; ALBERT, 2015), seja na constituição das leis do direito romano (cf. THOMAS, 1999), seja nas histórias que nos são contadas e que também contamos (narrativas históricas, nacionais, familiares, etc.) (cf. PIGLIA, 2016, p. 60), lá estão as palavras dando alguma forma, tentando com dificuldade conter a instabilidade própria do feixe de percepções e afetos que atravessam e constituem os indivíduos, os grupos e mesmo sociedades inteiras. Essa ordenação titubeante, mesmo provisória, é uma tentativa de estabelecer e manter algum sentido.

Esse processo de dar forma ao informe está presente também nos significados históricos do conceito de ficção. Karlheinz Stierle (2006), quando remonta à história do conceito de ficção, lembrando suas raízes latinas fingere, fictio, fictus, figura, e apoiado em Pigmaleão e no mito do artista que se apaixona pela figura esculpida, diz que "[o] primeiro

\footnotetext{
${ }^{1}$ Tese sustentada pelo filósofo alemão Ernst Cassirer em Mito e linguagem (2013), em que ele afirma que: "A consciência teórica, prática e estética, o mundo da linguagem e do conhecimento, da arte, do direito e o da moral, as formas fundamentais da comunidade e do Estado, todas elas se encontram originariamente ligadas à consciência mítico-religiosa. [...] Este vínculo originário entre a consciência linguística e a mítico-religiosa expressa-se, sobretudo, no fato de que todas as formações verbais aparecem outrossim como entidades míticas, providas de determinados poderes míticos, e de que a Palavra se converte numa espécie de arquipotência, onde radica todo o ser e todo o acontecer" (CASSIRER, 2013, p. 64).

${ }^{2}$ Basta pensar nas Metamorfoses, de Ovídio, a respeito das quais Karlheinz Stierle diz: "Para a formação da consciência na literatura moderna, nenhuma outra obra tornou-se tão importante como as Metamorfoses, que são em si mesmas como a ficção das ficções" (2006, p. 12).

${ }^{3}$ Destacamos, a esse respeito, o livro Há mundo por vir? (2015), de Déborah Danowski e Eduardo Viveiros de Castro, e os artigos: "O conceito de ficção", de Juan José Saer (2012); "Literatura como antropologia especulativa" (2015b), de Alexandre Nodari; "Ursa menor: notas sobre fiç̧ão científica e fantasia" (2018a) e "Introdução à Xenologia" (2018b), de Marco Antonio Valentim; e "Experiments in Thinking across Worlds" (2019), de Casper Bruun Jensen e Asli Kemiksiz.
} 
ato do fingere é dar forma ao informe, converter o barro em figura" (2006, p. 13). Stierle nos lembra também das semelhanças entre a palavra grega poiesis e a palavra latina fictio, “conceitos estéticos fundamentais, originários do pensamento grego e romano, cuja valia, na literatura pertencente ao círculo cultural europeu, permanece até hoje inalterável” (2006, p. 9). Se poiesis estaria ligada à criação (o que remeteria, inclusive, a um suposto criador originário), fictio estaria ligado ao par criação/imitação, isto é: dar forma/fingir.

Segundo Stierle, Wolfgang Iser teria nos oferecido uma definição precisa do que é a ficção "ao fazer do fictício uma categoria básica da compreensão antropológica do homem" (2006, p. 9). Se a ficção foi comumente descrita como oposta à realidade, no sistema tripartido de Iser (imaginário-ficção-real) ela é encarada como o dispositivo de transição entre o imaginário (aberto, inapreensível em sua totalidade, informe) e o real (imaginário recortado e estabilizado).

Em O fictício e o imaginário (2017), Iser vai nos dizer que são os "atos de fingir" (a repetição de dados da realidade na ficção) que fazem a passagem do imaginário para o real. Como a repetição da realidade na ficção não se dá por simples dedução exata, sendo também sempre modificada e infiltrada pelo imaginário, esses atos de fingir provocariam ao mesmo tempo "a irrealização do real e a realização do imaginário" (2017, p. 34). Nesse duplo movimento, segundo Iser, haveria uma transgressão de limites. O real repetido no texto e infiltrado pelo imaginário se converteria em signo (irrealizando-se, assim), enquanto o imaginário, ganhando forma através do ato de fingir, perderia "seu caráter difuso em favor de uma determinação" (2017, p. 33), isto é, seria realizado.

Esse duplo movimento, de acordo com Iser,

cria simultaneamente um pressuposto central que permite distinguir até que ponto as transgressões de limite que provoca (1) representam a condição para a reformulação do mundo formulado, (2) possibilitam a compreensão de um mundo reformulado e (3) permitem que tal acontecimento seja experimentado (2017, p. 34, grifo nosso).

Nesse parágrafo, Iser coloca de uma só tacada que (1) o mundo é formulado de determinada maneira, (2) pode ser modificado, isto é, reformulado, e (3) a ficção é um modo de experimentar outra formulação de mundo - e, dessa maneira, outros mundos. No sistema tripartido de Iser, o real, o fictício e o imaginário não funcionam como posições fixas e imutáveis, mas antes como funções que fazem algo ${ }^{4}$ circular pelo sistema, um sistema constituído por relações recíprocas. Nessas relações, a função desempenhada pelos "atos de

\footnotetext{
${ }^{4} \mathrm{O}$ emaranhado imaginário-fictício-real. 
fingir" (dar forma ao informe e repetir o real) é primordial porque estressa a própria "realidade do real", já que não trabalha em termos de polos opositivos (realidade x ficção), mas antes num modelo de reciprocidade que se retroalimenta positivamente (realidade e imaginário são mediados pela ficção (isto é, dar forma/imitar), realidade sempre e a cada vez re-infiltrada pelo imaginário, enquanto o imaginário é recortado temporariamente pela ficção). Nesse fluxo de mão dupla entre as três funções (imaginário, ficção, real; mas também real, ficção, imaginário), qualquer possível significado transcendental de cada uma delas é arruinado, sendo assim difícil distinguir uma da outra, tendo em vista que se compõem e atravessam.

$\mathrm{O}$ modelo tripartite de Iser parece ter efeitos semelhantes à maneira como outros autores concebem a concreção de uma complexidade - isto é, a ordenação titubeante de que falávamos no começo desta seção. O que nos interessa aqui não são apenas as variações entre o que poderíamos chamar de caos (informe) e cosmo (forma), mediados pela ficção, mas também as variações entre distintos sistemas caos $\Leftrightarrow$ cosmo, uma vez que, se levarmos em conta a retroalimentação positiva de que fala Iser, nunca se trata do mesmo caos e do mesmo cosmo.

O antropólogo Eduardo Viveiros de Castro, comentando as Mitológicas de Claude Lévi-Strauss, já falava que o mito dá conta justamente do processo de "especiação", isto é, a variação do regime pré-cosmológico (o "hetairismo ontológico" originário, o regime incessante de transformações que é próprio do mito) ao cosmológico (a transformação interditada em coisas e pessoas estáveis - ou melhor, que tendem à estabilidade mas nunca a alcançam, uma vez que no mito a instabilidade, a transformação, é a verdadeira tessitura daquilo que chamamos de "realidade") ${ }^{5}$. Como responde Lévi-Strauss quando Didier Eribon lhe pergunta o que é um mito: “[...] Se você interrogar um índio americano, seriam muitas as chances de que a resposta fosse esta: uma história do tempo em que os homens e os animais ainda não eram diferentes" (LÉVI-STRAUSS; ERIBON, 2005, p. 195-96). Essas variações entre o caos e o cosmo também foram trabalhadas com cuidado pela dupla Deleuze e Guattari em seus dois trabalhos principais, ainda que de maneira diferente de Iser $^{6}$ - tanto no terceiro

\footnotetext{
${ }^{5}$ Como diz Viveiros de Castro: "[...] o mito fala de um estado do ser onde os corpos e os nomes, as almas e as ações, o eu e o outro se interpenetram, mergulhados num mesmo meio pré-subjetivo e pré-objetivo" (2015a, p. 59). Para "hetairismo ontológico", conferir o artigo de Alexandre Nodari (2015a) sobre A paixão segundo G.H., de Clarice Lispector.

${ }^{6}$ Aqui é preciso traçar uma distinção importante, e que precisaria de uma análise mais detida em um artigo futuro. Enquanto Iser nos apresenta um sistema tripartite (real e imaginário mediados pela ficção, os três em retroalimentação), a nossa hipótese é que Deleuze e Guattari trabalhariam antes com o que Rodrigo Nunes
} 
capítulo de $O$ anti-Édipo (2011), "Bárbaros, selvagens e civilizados", quanto no platô "Acerca do Ritornelo", em Mil Platôs (2012).

N'O anti-Édipo, Deleuze e Guattari chegam à conclusão de que o maior temor de toda sociedade é aquilo que eles denominam de "fluxos descodificados do desejo" (os fluxos caóticos que dissolvem as formas sociais podendo levar consigo todo o socius de uma vez), e que por isso é preciso um grande investimento social para codificar os fluxos cuidadosamente ou sobrecodificá-los, e que a descodificação dos mesmos seria uma das características da sociedade capitalista - descodificação relativa, é bom que se diga, sempre re-codificada. As sociedades "primitivas", cujo exemplo metonímico é o povo Dogon, codificariam os fluxos de comida, sangue e sêmen em rituais iniciáticos os mais variados, rituais esses que organizam essas sociedades, determinando o que deve ser ingerido e o que precisa ser expelido, por exemplo, dentre outros maneirismos corporais. As sociedades "bárbaras", cujo exemplo metonímico é a China Imperial, sobrecodificariam os códigos anteriores com sua divisão hierárquica em classes ou castas estratificadas. Isso teria relação com o surgimento do Estado e seu poder centralizado. Já as sociedades ditas "civilizadas", que são as sociedades capitalistas, promoveriam a descodificação dos fluxos anteriormente codificados para em seguida re-codificá-los. Isso seria feito, dentre outras coisas, através do dinheiro, vetor de metamorfose, que transforma força de trabalho, meios de produção e matéria-prima em mercadoria, mercadoria em lucro, lucro em... e assim indefinidamente (Cf. DELEUZE; GUATTARI, 2011, p. 185-361).

Se no terceiro capítulo de $O$ anti-Édipo vemos três sociogêneses distintas e suas relações com o caos, no platô do ritornelo nós somos apresentados à repetição como aquilo que pode criar e manter uma ordem sobre o caos, aquilo que cria um território temporário. $\mathrm{O}$ principal exemplo de Deleuze e Guattari é o da criança no escuro e a cançoneta infantil. No escuro, os objetos perdem as suas delimitações, tornam-se ambíguos: uma estante pode se revelar um monstro, um rosto pode surgir em uma pilha de roupas. Essa indistinção e

(2014) descreveu como sendo as díades. Segundo Nunes, os pares conceituais de Deleuze e Guattari não seriam dualismos, mas antes díades, e "uma díade é uma relação de disjunção inclusiva entre dois termos indefinidos numa relação dinâmica de tensão, constituindo um campo em que os próprios termos se singularizam" (2014, p. 8, grifo nosso). O par caos-cosmo de Deleuze e Guattari, que na nossa hipótese pode ser lido como uma díade forças $\Leftrightarrow$ formas, é uma relação em que um termo não existe sem o outro. Novamente, não se trata de polos opositivos (de um lado o caos e de outro o cosmo, com uma passagem de um para o outro), mas antes de uma relação dinâmica de tensão: o cosmo é formado por forças caóticas temporariamente estabilizadas, assim como o caos é composto por forças que podem se estabilizar numa forma temporária. Arriscaríamos dizer, inclusive, que a leitura opositiva (caos x cosmo) é fruto de um problema de perspectiva. Afinal, do ponto de vista da forma (cosmo), o informe (caos) só pode ser o seu oposto. Mas do ponto de vista das forças (caos), talvez se possa perceber que toda forma é caos coagulado. 
ambiguidade é própria da perda de sentido. Para se acalmar, para criar uma proteção a essa instabilidade, um território a salvo dessa terrível ambiguidade, a criança canta uma canção infantil repetidamente. Há ainda, como dizem Deleuze e Guattari, uma relação entre essa repetição, essas marcas que criam um território, um código, um sentido, e as cosmogonias: "Do caos nascem os Meios e os Ritmos. É o assunto das cosmogonias muito antigas" (DELEUZE; GUATTARI, 2012, p. 124, grifo do autor). E é claro que esse é o assunto das cosmogonias, uma vez que o seu efeito é justamente dar forma ao informe, isto é, criar uma provisória estabilidade possível.

Embora possa parecer um movimento estranho, podemos aproximar o ritornelo de Deleuze e Guattari a algo que o escritor Ricardo Piglia disse sobre a narração. Em Las tres vanguardias - Saer, Puig, Walsh (2016), que reúne algumas de suas aulas dadas na Universidad de Buenos Aires em 1990, Piglia fala em determinado momento do lugar da novela na sociedade e da relação entre a ficção e os relatos sociais - entre outras coisas, a disputa social com a ficção produzida pelo Estado, essa sorte de "narrativa oficial" que se pretende unívoca à força (o Estado ditatorial argentino é o exemplo utilizado por ele). Mas o que Piglia apresenta que pode nos interessar aqui é a constatação de que existem "certos modos de narrar" e que esses modos como que constituem cada sociedade:

\footnotetext{
Podemos imaginar que se conhecêssemos o conjunto de narrações que circulam na cidade de Buenos Aires em um dia, conheceríamos um tipo particular de funcionamento desta cidade com bastante precisão. [...] Se tivéssemos a possibilidade, fantástica, de dispor de todas essas narrações, poderíamos detectar as grandes formas, os grandes núcleos formais a partir dos quais se constituem os relatos sociais. E notaríamos com clareza que estamos determinados por certos modos de narrar. Do mesmo modo que certas estruturas da língua nos ajudam a falar, existem estruturas narrativas dadas que usamos sem pensar e funcionam como elementos no interior dos quais os sujeitos construímos nossas paixões e estilos pessoais (PIGLIA, 2016, p. 60-6, grifo nosso, tradução nossa).
}

Em Aqui, América Latina, Josefina Ludmer afirma algo semelhante ao caracterizar a imaginação pública como uma "fábrica do real”: "A imaginação pública seria um trabalho social, anônimo e coletivo de construção de realidade" (2013, p. 9). Esses certos "modos de narrar" que nos determinam, ou a imaginação pública como "fábrica do real”, talvez partilhem uma raiz comum com o mito. Mas o certo é que, atualmente, calcificados em grandes narrativas sociais - o dinheiro, a nação, o Estado, a família, o "empreendedorismo", etc. -, esses "modos de narrar" parecem ter embotado tanto a possibilidade de outras narrativas que qualquer construção alternativa da realidade parece impossível. A desvalorização de outros 
modos de narrar é também a desvalorização de outros modos de perceber e estar no mundo ou em outros mundos (que é o que esperamos demonstrar).

No último parágrafo de seu já conhecido texto "O conceito de ficção" (2012), o escritor argentino Juan José Saer fala de passagem, sem desenvolver muito, da literatura como uma espécie de "antropologia especulativa". Segundo Saer, à ficção não caberia um modo de reivindicação do falso, como alguns insistem em dizer, mas antes um modo de pôr em tensão o conceito de "verdadeiro". A ficção "[n]ão nega uma suposta realidade objetiva, ao contrário, submerge-se em sua turbulência, desdenhando a atitude ingênua que consiste em pretender saber de antemão como essa realidade se conforma" (SAER, 2012, p. 2-3, grifo nosso). Para a hipótese de Saer, o fundamental parece ser a necessidade de submersão - seja na "realidade objetiva", seja na "massa pantanosa do empírico e do imaginário" (2012, p. 3). O realismo ingênuo seria aquele que já toma de antemão a "realidade como dada", e faz isso sem perceber, como poderia dizer Piglia, que essa "realidade" é determinada por certos "modos de narrar".

Num primeiro momento, se lida apressadamente, a asserção de Saer acerca da literatura como "antropologia especulativa" poderia ainda assim soar antropocêntrica - a literatura como um "estudo especulativo do que é o homem", ou algo do gênero. Mas é justamente a preocupação de Saer com a submersão no feixe de percepções e afetos que compõe o empírico e o imaginário o que parece deixar a porta aberta para uma especulação aquém e além do dito "humano". Se essa asserção de Saer fosse lida tendo em mente a "antropologia" como aquela disciplina teorizada e praticada, por exemplo, por Eduardo Viveiros de Castro, Tânia Stolze Lima e Aparecida Vilaça, isto é, uma antropologia comprometida com a "descolonização permanente do pensamento" (VIVEIROS DE CASTRO, 2015a, p. 20), a sua aproximação à literatura seria de uma potência tremenda para os dois campos - o da ficção e o da disciplina antropológica.

Uma tal literatura, enquanto "antropologia especulativa", poderia nos devolver "uma imagem de nós mesmos na qual não nos reconhecemos", como diz Patrice Maniglier acerca da antropologia (MANIGLIER, 2005, p. 773-74 apud VIVEIROS DE CASTRO, 2015a, p. 21). De qualquer forma, aqui se trata de uma literatura - e de uma antropologia - que "leva a sério", como diz Viveiros de Castro (2002, p. 129), o outro e o seu pensamento, isto é, outros modos de vida e de estar no mundo e percebê-lo, ou mesmo outros mundos. Para a antropologia, é claro, isso quer dizer levar a sério os povos estudados e que coproduzem a teoria antropológica. Mas como se dá esse gesto e quais consequência podemos tirar dele? 
[O] que acontece quando se leva o pensamento nativo a sério? Quando o propósito do antropólogo deixa de ser o de explicar, interpretar, contextualizar, racionalizar esse pensamento, e passa a ser o de o utilizar, tirar suas consequências, verificar os efeitos que ele pode produzir no nosso? O que é pensar o pensamento nativo? Pensar, digo, sem pensar se aquilo que pensamos (o outro pensamento) é "aparentemente irracional", ou pior ainda, naturalmente racional, mas pensá-lo como algo que não se pensa nos termos dessa alternativa, algo inteiramente alheio a esse jogo? Levar a sério é, para começar, não neutralizar. É, por exemplo, pôr entre parênteses a questão de saber se e como tal pensamento ilustra universais cognitivos da espécie humana, explica-se por certos modos de transmissão social do conhecimento, exprime uma visão de mundo culturalmente particular, valida funcionalmente a distribuição do poder político, e outras tantas formas de neutralização do pensamento alheio. Suspender tal questão ou, pelo menos, evitar encerrar a antropologia nela; decidir, por exemplo, pensar o outro pensamento apenas (digamos assim) como uma atualização de virtualidades insuspeitas do pensar (VIVEIROS DE CASTRO, 2002, p. 129).

Para a literatura, no entanto, "levar a sério" o outro e o seu pensamento pode significar não se levar tão a sério, isto é, colocar-se em dúvida, não ter um apego assim tão grande à dita "realidade objetiva" nem à "identificação". A antropologia comprometida com a “descolonização permanente do pensamento", aliás, como já referido, só é possível quando o antropólogo faz o penoso esforço de se desidentificar - que é o primeiro passo para "levar a sério" o outro. Em contraste à literatura preocupada com a identificação do leitor através de uma reprodução "ingênua" da realidade (marcada por "modos de narrar" repetidos à exaustão), aquela que busca o contrário, isto é, a desidentificação, o estranhamento, e que atravessa o espelho como Alice, pode ser dita "especulativa". E, como diz Ludmer: "O sentido da especulação é a procura de algumas palavras e formas, modos de significar e regimes de sentido, que nos permitam ver como funciona a fábrica de realidade para poder encontrar seu avesso" (2013, p. 10, grifo nosso).

\section{A “virada ontológica” e suas implicações}

Se formos à etimologia latina das palavras "especulação" e "espelho", encontraremos semelhanças. Ambas provavelmente compartilham a raiz indo-europeia spek-, ou a latina specere - que significam "olhar"7. No caso de "especulação", segundo o Dicionário Escolar Latino-Português (1962), podemos citar specula, substantivo que significa "lugar de observação, [...] lugar elevado, observatório [...]", e speculator, substantivo que significa

\footnotetext{
${ }^{7}$ Segundo A grammar of Modern Indo-European (2017): “[...] the root of verb spekjō, look, is spek-, which does not necessarily mean to look, or I look, or looking, but merely expresses vaguely the idea of looking, and possibly cannot be used as a part of speech without terminations" (2017, p. 151, grifo do autor).
} 
“[o]bservador, espião, batedor, explorador [...]” (1962, p. 935). No caso de "espelho", a palavra latina é speculum.

É do espelho, aliás, e da possibilidade de atravessá-lo, como faz Alice, que Eduardo Viveiros de Castro certa vez lançou mão para começar a esboçar o que ele entendia por "aprender a ver em antropologia" e as suas consequências (VIVEIROS DE CASTRO, 2015b, p. 3). Isso aconteceu em uma fala em homenagem à antropóloga Marilyn Strathern na University of Cambridge, que acabou se tornando o artigo Who is afraid of the ontological Wolf? (2015b). No começo desse artigo, Viveiros de Castro traçou o paralelo entre "aprender a ver em antropologia" e uma das cenas iniciais de Através do Espelho e o que Alice encontrou lá (2010), de Lewis Carroll, a cena em que Alice observa a Casa do Espelho. A cena a que Viveiros de Castro se refere, o primeiro momento de Alice do outro lado do espelho, é: "Em seguida começou a olhar em volta e notou que o que podia ser visto da sala anterior era bastante banal e desinteressante, mas todo o resto era tão diferente quanto possível” (CARROLL, 2010). Segundo Viveiros de Castro, “[e]sse momento de atravessar o espelho (em qualquer direção, apresso-me em adicionar) evoca fortemente a assim chamada 'virada ontológica', à qual o meu nome, dentre alguns outros delinquentes, foi associado" (VIVEIROS DE CASTRO, 2015b, p. 3, tradução nossa).

Viveiros de Castro cita, então, três estímulos que ele considera responsáveis pela "virada ontológica" que vêm contaminando, pelo menos desde o começo da década de 90, a antropologia, a filosofia e os estudos sobre ciência e tecnologia. A ontologia, empresa anteriormente interditada em detrimento do estudo epistemológico, sua qualidade e alcance, teria ganhado velocidade novamente por conta da "crise da representação", do surgimento dos estudos sobre ciência e tecnologia e da acentuação das catástrofes climáticas, econômicas e subjetivas que compõem o chamado "Antropoceno" - catástrofes essas que imbricaram terrível e inextrincavelmente geopolítica e geofísica, economia e ecologia, explodindo de vez o "grande divisor" entre as ciências naturais e sociais; entre, enfim, "Natureza" e "Cultura" (Cf. VIVEIROS DE CASTRO, 2015b, p. 4).

A “crise da representação" a que Viveiros de Castro se refere como sendo o primeiro estímulo para a "virada ontológica", segundo o próprio, não seria exatamente a mesma traçada pela crítica pós-moderna. Ao invés de focar na "crítica epistemológica da autoridade etnográfica", isto é, a possibilidade ou não de representação do outro e sua cultura, concentraria esforços antes 
no status representacional do objeto do discurso etnográfico, ou seja, sua "natureza" como consistindo em representações (culturas, visões de mundo, ideologias) que "representam" outra coisa (diferenciais de poder, relações de produção, restrições ecológicas, universais cognitivos) (VIVEIROS DE CASTRO, 2015b, p. 4, grifado no original, tradução nossa).

Fruto de críticas internas à teoria etnográfica, a "crise da representação" acabaria forçando, mais tarde, a necessidade de redefinir a própria antropologia enquanto disciplina (redefinição essa que Viveiros de Castro esboça e que veremos melhor no correr desta seção).

Se após a crítica kantiana a discussão ontológica havia sido interditada, ou, quando muito, delegada às ciências duras (numa transição da discussão ontológica para a ontogenética), o surgimento da antropologia da ciência, cujo nome mais famoso é provavelmente o de Bruno Latour, veio desestabilizar a primazia absoluta que essas ciências teriam em relação à apreensão da realidade. Isso teria acontecido, dentre outras coisas, porque a antropologia da ciência faz uma descrição etnográfica dos procedimentos científicos, isto é, uma investigação empírica acerca de como se constituem os seus pressupostos basilares, demonstrando assim que não há neutralidade pura e não contaminada minimamente que seja pelos mais variados a priori, sejam eles políticos, ideológicos ou mesmo culturais. E, de acordo com Viveiros de Castro,

[a] descrição etnográfica da "ciência" (tanto a prática real das ciências quanto os usos políticos do conceito no singular) teve profundas consequências para a antropologia como um todo. $\mathrm{E}$ isso por uma razão simples, mas abrangente: a oposição moderna entre ciência e não-ciência é um 'modelo de' e um 'modelo para' a divisão mais ampla que separa a modernidade ocidental das demais, dos bárbaros e dos primitivos (VIVEIROS DE CASTRO, 2015b, p. 5) ${ }^{8}$.

Tal descrição deixaria à mostra, dentre outras coisas, como a "epistemologia [ocidental] vai se tornando insidiosamente ontologia" (VIVEIROS DE CASTRO, 2015b, p. 5), e é dessa forma que qualquer outra epistemologia é também desvalorizada.

Mas precisamos definir o que queremos dizer quando dizemos "ontologia", e só através dessa definição é que se pode tirar todas as implicações - teóricas e políticas - do que significa pensar em "múltiplas ontologias" (que é uma das consequências possíveis da "virada ontológica"). Como Peter Skafish, Gildas Salmon e Pierre Charbonnier lembram ainda na

\footnotetext{
${ }^{8}$ É bom ter em mente, como lembra Viveiros de Castro, que a "descrição etnográfica" das práticas científicas e dos seus usos políticos não é feita abolindo a distinção entre "ciência" e "não-ciência", como numa relativização absoluta que traria consequências danosas à sociedade, mas antes buscava "[multiplicar e diferenciar] essa distinção em uma nuvem de práticas com demandas e obrigações específicas" (VIVEIROS DE CASTRO, 2015b, p. 5).
} 
introdução de Comparative metaphysics (2017), a chamada "virada ontológica" na antropologia gerou várias suspeitas, dentre elas a de que "ontologia" seria apenas um novo nome para "cultura". Dessa forma, seria apenas mais uma maneira de conceber o mundo, mas o mundo mesmo ainda seria aquele dos "modernos", isto é, uno e universal (Cf. CHARBONNIER; SALMON; SKAFISH, 2017, p. 4). É para fugir desse novo relativismo que Viveiros de Castro sugere que, se é para ser sinônimo de algo, ontologia seria antes um sinônimo de "natureza":

Ontologia, como eu a entendo, é uma máquina de guerra filosófica antiepistemológica e contra-cultural (nos dois sentidos de "contra-cultural"). Se a ontologia fosse "apenas outro nome para" qualquer coisa, eu sugeriria que deveria ter sido Natureza (VIVEIROS DE CASTRO, 2015b, p. 9, grifo do autor).

Do multiculturalismo ao multinaturalismo em apenas uma frase: a questão não seria mais como os diversos povos conceitualizam (isto é, representam) a natureza, mas antes como eles experimentam outra natureza, outro mundo. O "multinaturalismo" está na base do "perspectivismo ameríndio" conforme conceitualizado por Viveiros de Castro e Tânia Stolze Lima, talvez a contribuição mais poderosa à chamada "virada ontológica". 9

Já o terceiro estímulo à "virada ontológica" mencionado por Viveiros de Castro, e sobre o qual o autor não se demora nesse artigo de 2015, é a catástrofe ecológica com a qual já convivemos e cuja acentuação apresenta um horizonte próximo ainda mais desafiador. Tal catástrofe, obviamente indissociável das crises econômicas e sociais justamente por ser efeito de um modo particular de vida, modo esse baseado no extrativismo, na produção desenfreada de mercadorias e alavancado pela queima de combustíveis fósseis, dentre outras coisas, teria feito com que, segundo Viveiros de Castro, a física desse lugar à metafísica "quando 'cultura' e 'natureza' trocaram seus tradicionais locais de, respectivamente, figura e fundo" (2015b, p.

\footnotetext{
${ }^{9} \mathrm{O}$ conceito de perspectivismo ameríndio proposto por Viveiros de Castro e Tânia Stolze Lima se ancora em três vértices indispensáveis sem os quais a sua máquina conceitual não "funciona". São eles o perspectivismo interespecífico, o multinaturalismo ontológico e a alteridade canibal, que "formam assim os três vértices de uma alter-antropologia indígena que é uma transformação simétrica e inversa da antropologia ocidental" (VIVEIROS DE CASTRO, 2015a, p. 34). Como cada espécie vê a si mesma como "humana", a lógica que rege o perspectivismo é a da predação (o canibalismo), quem é caça e quem é predador. Mas como todas as espécies não podem ser "humanas" ao mesmo tempo, a ontologia é "multinaturalista", isto é, cada espécie é "humana" em seu mundo. Daí o risco tremendo em ser capturado pela perspectiva de outra espécie, perigoso encontro que abunda nas mitologias ameríndias. É bom levar em conta também, como diz Viveiros de Castro, que se trata mais de um estatuto de "personitude" do que de uma "humanidade", tendo em vista que "o conceito de pessoa centro de intencionalidade constituído por uma diferença de potencial interna - é anterior e superior logicamente ao conceito de humano" (VIVEIROS DE CASTRO, 2015a, p. 47, grifo do autor). Ou, como diria Jakob von Uexküll, cada um é sujeito em seu próprio "mundo-circundante" (Cf. UEXKÜLL, 2016). Falaremos melhor de Uexküll e seu conceito de "mundo-circundante" na terceira seção desse artigo.
} 
6, tradução nossa). É dessa forma que a emergência da natureza (no duplo sentido) teria contribuído para a "virada ontológica".

Ainda em Who is afraid of the Ontological Wolf?, Viveiros de Castro vai nos dizer que uma das implicações de se "levar a sério" o outro e o seu pensamento é que "[a] antropologia se torna metafísica comparada assim como a metafísica se torna etnografia comparada" (VIVEIROS DE CASTRO, 2015b, p. 7). Pensar a antropologia como "metafísica comparada" provoca ainda outra torção à frase de Saer. Porque, agora, do ponto de vista da ficção, mais do que especular sobre diferentes culturas, isto é, ficcionalizar perspectivas culturais, o que se poderia alcançar é a comparação, a torção e a equivocação de mundos.

De acordo com a raiz etimológica das palavras, e reverberando ainda a frase já citada de Patrice Maniglier, se for para falar de reflexo, uma verdadeira "ficção especulativa" deveria, portanto, refletir no espelho uma imagem de nós mesmos na qual não nos reconheceríamos.

É bom lembrar, ainda tendo em vista o "perspectivismo ameríndio" como um dos principais vetores da assim chamada "virada ontológica", que "perspectiva" compartilha com "especulação" e "espelho" a mesma raiz indo-europeia "spek-", só que com o acréscimo do prefixo "per-", que significa "através de, por, por entre" (1962, p. 718). Nesse caso, atravessar o espelho, feito Alice, pode ser entendido também como atravessar o (modo de) olhar.

\section{Atravessar, mas como? O “expresso transumwéltico” de Gabriel Catren}

"Os metafísicos de Tlön não buscam a verdade nem sequer a verossimilhança: buscam o assombro" (BORGES, 2018, p. 22). Essa conhecida frase de Borges pode nos ajudar a pensar a especulação e mesmo a antropologia como "metafísica comparada".

Para além da comparação entre mundos, seria interessante pensar como seria possível experimentar outros mundos. Nesse aspecto, o excelente livro de Gabriel Catren, Pleromática o las mareaciones de Elsinor (2017), pode nos ajudar muito. Em seu livro, Catren traça uma estranha aliança entre Kant e Espinosa, uma aliança entre o transcendentalismo (as estruturas transcendentais que determinam a experiência) e o imanentismo (o que ele chama de "insubstância" ou "pleroma", isto é, aquilo que excederia todo sujeito transcendental, o “campo experiencial infinito e impessoal” (Cf. CATREN, 2017, p. 17)). Essa estranha aliança deixa a porta aberta para se buscar o assombro, e não a verdade. O assombro seria justamente a experiência alterada, isto é, a possibilidade de alteração da experiência, de alteração da 
"estrutura transcendental". A alteração da "estrutura transcendental" permitiria que se experimente outro "mundo-circundante" (ou Umwelt, como chamava Jakob von Uexküll ${ }^{10}$ ), outro "mundo de sentido". O que o assombro nos mostra é que não há verdade metafísica última a ser desvelada, essência fixa ou imutável a ser apreendida, mas antes sempre um conjunto de relações em relações. As relações em relações são modos de explorar o "pleroma" sem nunca esgotá-lo ou acessá-lo sem mediação. Ao compormos relações (por exemplo, aquilo que nos habituamos a chamar de "eu”) com diferentes relações (por exemplo, uma substância química), modificamos os modos de exploração, construindo assim outros efeitos.

A questão é: como se altera a estrutura transcendental? O que faria da estrutura algo transcendental não seria justamente a impossibilidade de alterá-la? A esse respeito, Catren vai nos dizer o seguinte:

[O]s graus empíricos de liberdade de um carrapato e de um ser humano - e, portanto, os Umwelten nos quais eles podem se mover - não são os mesmos. Se o sujeito quiser radicalizar o escopo de sua exploração além do seu Umwelt transcendental-dependente, deve abordar a tarefa de realizar variações transcendentais (trans-variações) da própria estrutura transcendental que possibilita sua experiência. Efetuar tais trans-variações significa perturbar, deformar ou induzir mutações do próprio quadro transcendental que possibilite sua experiência (em suas dimensões conceitual, perceptiva, afetiva, social, linguística, sexual, histórica e cultural). Então, finalmente, o que chamo de sujeito especulativo é um sujeito que, além de poder modificar sua experiência real, alterando seu estado em seu Umwelt, também gera mutações do próprio quadro transcendental que define o horizonte "umwéltico" de suas possíveis experiências (CATREN, 2016, p. 4, grifo do autor, tradução nossa).

Catren propõe que é possível alterar a "estrutura transcendental" através da arte, da ciência e da política, assim como através de outras "práticas de expansão da experiência". Ainda segundo o filósofo:

arte, ciência e política (dentre outras práticas possíveis para a expansão da experiência) operam transgressões diferenciais dos limites (empíricos e transcendentais) da experiência humana, perseguindo as interzonas transumvélticas do campo experiencial impessoal (CATREN, 2016, p. 5, tradução nossa).

Dito de outra forma, a arte, a ciência, a política e diversas outras práticas não permitiriam apenas que nós sentíssemos, percebêssemos e compreendêssemos de uma

\footnotetext{
${ }^{10}$ A obra de Jakob von Uexküll, Andanzas por los mundos circundantes de los animales y los hombres (2016), e que influenciou filósofos tão diferentes quanto Ernest Cassirer, Martin Heidegger, Peter Sloterdijk, Gilles Deleuze e Giorgio Agamben, dentre outros, é de importância fundamental também para Gabriel Catren. Como Uexkülll explica ainda no prólogo de seu livro: "tudo o que um sujeito percebe se torna seu mundo perceptual, e todo o seu agir se torna o seu mundo efetivo. Mundo perceptual e mundo efetivo conformam juntos uma unidade fechada: o mundo-circundante" (2016, p. 35, tradução nossa).
} 
maneira diferente, como seriam capazes de modificar também a nossa "estrutura transcendental", isto é, nosso campo de experiências possíveis. Em suma, essas diversas práticas "também podem forçar variações transcendentais das condições a priori de perceptibilidade, afetabilidade, conceitualidade, sociabilidade e produção" (CATREN, 2016, p. 5).

Aos diversos modos de alteração (ou expansão) da experiência (e, consequentemente, de visita a outros "meios-circundantes"), Catren vai dar o nome de "expressos transumwélticos" (Cf. CATREN, 2016, p. 5). Esses "expressos transumwélticos” podem nos ajudar a pensar a experiência literária, ainda mais tendo em vista que, como nos lembra Alexandre Nodari, "escrever e ler ficções é alterar-se, mudar a própria posição existencial, resituar a própria existência diante de uma nova inexistência descoberta" (NODARI, 2015b, p. 82).

A experiência literária talvez seja um dos mais poderosos "expressos transumwélticos", uma vez que pode nos dar não apenas "acesso imaginativo a outros eus", como disse o escritor norte-americano David Foster Wallace (2012, p. 22), a outros "egos experimentais" (NODARI, 2015b, p. 82) e a outros modos de existência ("Como é ser um morcego?", título de um célebre artigo de Nagel (2005)), como também, num outro movimento, altera as nossas experiências cotidianas, as experiências dentro do nosso próprio "mundo-circundante" - e, portanto, as experiências que são possíveis nele -, esgarçando, distendendo esse mundo. A experiência literária faz com que possamos perceber coisas que antes nos eram imperceptíveis - não apenas imagens e sensações, modos de existência outros e pensamentos distintos, mas também velocidades, intensidades, temperaturas, texturas e temporalidades que através da leitura atravessam o corpo ${ }^{11}$.

\section{Considerações finais: ficção perspectivista, xenologia e cosmopolítica}

Se o "realismo moderno", segundo Jacques Rancière, tinha uma relação de pressuposição recíproca para com a democracia, uma vez que a igualdade republicana seria espelhada na "cosmologia ficcional” (Cf. RANCIÈRE, 2010, p. 78), agora que muitos dos ideais democráticos vêm sendo postos em xeque pela ascensão de governos autoritários de

11 Para a relação entre literatura e outros "modos de existência", recomendamos novamente o artigo de Alexandre Nodari (2015b, p. 81-82). Ainda sobre a "experiência literária" e o esboço de sua ontologia, assim como os seus possíveis desdobramentos, recomendamos "Quase-evento: a estoricidade da experiência literária" (NODARI, 2017). 
extrema-direita - e com a acentuação das crises ecológicas, político-econômicas e existenciais que vivemos -, talvez a literatura dita especulativa esteja mais bem equipada para lidar com o problema. Se Jacques Rancière foi capaz de pensar "as políticas da escrita" a partir da relação entre o "realismo moderno" e a "igualdade democrática", com personagens antes invisibilizados tendo agência na narrativa, talvez apenas isso já não seja mais o suficiente ${ }^{12}$. Talvez já esteja na hora de pensarmos uma "cosmopolítica" da ficção. Entendemos "cosmopolítica", aqui, à maneira como ela é proposta por Isabelle Stengers, isto é, não como o "mundo comum" da "paz perpétua" kantiana, mas sim como a tentativa de se abrir a uma pluralidade de mundos ${ }^{13}$ (Cf. STENGERS, 2018). Como nos lembra Ursula Le Guin acerca da asfixia desse projeto de homogeneização do que viria a ser um "mundo comum":

\begin{abstract}
A monstruosa homogeneização do mundo agora quase destruiu o mapa, qualquer mapa, tornando todos os lugares exatamente como em qualquer outro lugar, e não deixando espaços em branco. Não há terras desconhecidas. Uma lanchonete de hambúrguer e um café em cada quarteirão repetidos para sempre. Nenhum outro; nada de estranho. Como no conjunto fractal de Mandelbrot, o enormemente grande e o infinitesimalmente pequeno são exatamente os mesmos; e o mesmo leva sempre ao mesmo novamente: não há outro; não há escapatória, porque não há outro lugar (LE GUIN, 2007, p. 5).
\end{abstract}

A "cosmopolítica" de que falamos seria justamente aquela capaz de abrir fendas para traçar uma multiplicidade de saídas. A nossa hipótese é que só é possível pensar uma "cosmopolítica" da fícção a partir da ficção dita "especulativa", e isso não por ela ter sido capaz de representar uma realidade que lentamente vai se tornando distopia, mas antes por sempre ter sido um manancial de especulação e experimentação de outras realidades e formas de consciência. Isso fica claro uma vez que a "ficção especulativa" sempre compartilhou de e esteve aberta a - outras "ontologias". Não apenas a outros mundos, mas a outros modos de ser e estar no mundo, a toda uma infinidade de modos não-humanos, espectrais e mesmo xenomorfos. No que entendemos aqui por "ficção especulativa" não se enquadrariam apenas (ou necessariamente) os títulos que são descritos assim somente sob uma ótica de mercado. Mas sim livros variados, da força demoníaca que impulsiona a dissolução da forma humana em A paixão segundo G.H., de Clarice Lispector (2009), à indiscernibilidade mulher-cachorro em Casamata, de Raïssa de Góes (2019); da cosmologia da tribo kaajapukugi em A morte e o

\footnotetext{
${ }^{12} \mathrm{O}$ exemplo paradigmático citado por Rancière é a personagem Felicité, do conto "Um coração simples", de Gustav Flaubert.

${ }^{13}$ Aqui é bom ressaltar que, embora não estejamos associando as "políticas da escrita" de Rancière necessariamente ao cosmopolitismo kantiano da "paz perpétua", entendemos que o limite da proposta do filósofo francês é não levar em conta variações ontológicas. A "cosmologia ficcional" de que fala Rancière se refere a um igualitarismo social, mas não parece aberta (ou ao menos Rancière não esboça essa abertura) a outros mundos.
} 
meteoro, de Joca Reiners Terron (2019), ao monstro semiótico que habita e desarticula a linguagem no Catatau, de Paulo Leminski (1989).

Assim, o que se acostumou a chamar (pejorativamente ou não) de "ficção especulativa" talvez devesse ser chamado, antes, e melhor ainda compreendido, como "fícção perspectivista" 14 , isto é, aquela que atravessa outros modos de ver e, consequentemente, de narrar.

Num certo sentido, toda literatura é perspectivista, como sabemos, uma vez que parte de um certo modo de narrar e de um certo olhar sobre o mundo - por assim dizer. Mas quando esse modo de narrar está inserido num discurso hegemônico mais amplo (a "mitofísica"15 ocidental, por exemplo), esse perspectivismo na verdade não passa de um relativismo pueril: pontos de vista diferentes sobre a mesma coisa (o mundo), que continua fixo e imutável - e é natural que seja assim, dizem. Mas a maneira como entendemos "perspectiva", nesse contexto, é diferente. O perspectivismo que reivindicamos aqui, na esteira do perspectivismo ameríndio conceitualizado por Viveiros de Castro e Tânia Stolze Lima, é aquele da equivocidade material - quero dizer, não um ponto de vista sobre o mundo (que seria estável e unívoco), mas antes "um ponto de vista que é mundo", dando a ver, assim, uma multiplicidade de mundos. Como disse Viveiros de Castro em uma entrevista:

Não existem "visões de mundo" (muitas visões de um só mundo), mas mundos de visão, mundos compostos de uma multiplicidade de visões eles próprios, onde cada ser, cada elemento do mundo é uma visão no mundo, do mundo - é mundo. Para este tipo de ontologia, o problema que se coloca não é o da "tolerância" (só os donos do poder são "tolerantes"), mas o da diplomacia ou negociação intermundos (VIVEIROS DE CASTRO, 2015c).

Esse perspectivismo não é apenas físico, mas metafísico - se entendermos "ontologia", assim como sugere Viveiros de Castro, como "natureza". Não há um só mundo, não há um só sujeito universal (isso que se habitou a chamar de "humano") debruçado sobre

\footnotetext{
${ }^{14}$ A tentativa de pensar as consequências do perspectivismo para a teoria da literatura não são recentes. Isso pode ser visto, de maneiras diferentes, em textos como o de Ana Carolina Cernicchiaro (2010), assim como nos já referidos de Alexandre Nodari (2015b) e Marco Antonio Valentim (2018a).

${ }^{15}$ É interessante lembrar a frase de Viveiros de Castro acerca da metafísica: "Toda metafísica é mitofísica" (VIVEIROS DE CASTRO, 2017, p. 261, grifo do autor). Porque é por considerarem a sua "metafísica" como algo natural (a metafísica certa, por assim dizer) que o senso comum dito "ocidental" vê nos povos nãomodernos uma crença que só pode ser, pejorativamente, da ordem do "mito", do misticismo e da superstição. Mas se entendermos toda "metafísica" como uma "mitofísica", isto é, pensando o mito como "verdade em variação" (VIVEIROS DE CASTRO, 2017, p. 261), positivamente, podemos colocar em dúvida o nosso próprio sistema de crenças e "multiplicar o nosso mundo". Porque, como nos lembra ainda Viveiros de Castro, "O papel da antropologia, então, não é o de explicar o mundo do outro, mas antes multiplicar o nosso mundo" (VIVEIROS DE CASTRO, 2017, p. 266, grifo do autor).
} 
um cosmos que é seu objeto de estudo. O "humano", aliás, "é muito mais um pronome do que um nome" (VIVEIROS DE CASTRO, 2008, p. 113). O "humano" é, como diz Viveiros de Castro, "sempre a posição do sujeito, no sentido linguístico da palavra, [isto é,] é aquele que diz 'eu”" (VIVEIROS DE CASTRO, 2008, p. 112).

Se no começo desse artigo, com o auxílio de Juan José Saer e Alexandre Nodari, pensamos a ficção como "antropologia especulativa", agora talvez possamos repensar também o papel da antropologia nessa equação. Se com a ajuda da antropologia de Viveiros de Castro e Tânia Stolze Lima conseguimos teorizar não mais uma "ficção especulativa", mas antes uma ficção perspectivista, agora podemos compreender também que o que entendemos por "antropologia" já não pode mais se assentar apenas sobre o anthropos. Poderia tratar-se agora, como vem desenvolvendo Marco Antonio Valentim, de uma "xenologia":

E talvez a xenologia só possa mesmo realizar-se como literatura, na medida em que esta for capaz de comportar mais de um mundo. Pelo contrário, toda teoria seria xenologicamente limitada, devido à sua univocidade essencial tanto na forma (uma só voz, uma não-voz) quanto no conteúdo (um só sentido, horizonte único). Ou é possível uma teoria intrinsecamente equívoca, polifônica? Seja como for, a xenologia é impossível enquanto se pensa dentro dos limites de um só mundo (VALENTIM, 2018b, p. 44).

A ficção perspectivista, a xenologia e a especulação mitofísica, dessa maneira, se confundiriam assim como diferentes "expressos transumwélticos". E uma verdadeira literatura cosmopolítica só pode ser perspectivista.

\section{REFERÊNCIAS}

BORGES, Jorge Luis. Ficções. São Paulo: Companhia das Letras, 2018.

CARROLL, Lewis. Através do Espelho e o que Alice encontrou por lá. São Paulo: Jorge Zahar, 2010. [Versão eletrônica].

CASSIN, Barbara. O efeito sofístico. São Paulo: Editora 34, [1995] 2005.

CASSIN, Barbara. Sofística, performance, performativo. In: Anais de Filosofia Clássica, v. 3 $\mathrm{n}^{\circ}$ 6, 2009. Tradução publicada em v. 10, n. 20, 2016. Tradução de Fernando Santoro, em 2018.

CASSIRER, Ernst. Mito e linguagem. São Paulo: Perspectiva, 2013. 
CATREN, Gabriel. The "Trans-Umweltic Express". Glass-bead, 2016. Disponível em: http://www.glass-bead.org/article/the-trans-umweltic-express/?lang=enview. Acesso em: 15 abr. 2020.

CATREN, Gabriel. Pleromática o las mareaciones de Elsinor. Buenos Aires: Hekht Libros, 2017.

CERNICCHIARO, Ana. Perspectivismos. Sopro, n. 22, 2010. Disponível em:

http://culturaebarbarie.org/sopro/verbetes/perspectivismos.html. Acesso em: 15 abr. 2020.

CHARBONNIER, Pierre; SALMON, Gildas; SKAFISH, Peter (org.): Comparative metaphysics: ontology after anthropology. Lanham: Rowman \& Littlefield International, 2017.

DANOWSKI, Déborah; VIVEIROS DE CASTRO, Eduardo. Há mundo por vir?.

Florianópolis, SC: Cultura e Barbárie e Instituto Socioambiental, 2015.

DELEUZE, Gilles; GUATTARI, Félix. O Anti-Édipo. São Paulo: Editora 34, 2011.

DELEUZE, Gilles ; GUATTARI, Félix. Mil Platôs volume 4. São Paulo: Editora 34, 2012

DETIENNE, Marcel. Os mestres da verdade na Grécia Arcaica. Rio de Janeiro: Zahar, 1988.

FARIA, Ernesto (org.). Dicionário Escolar Latino-Português. Campanha nacional de material de ensino, 1962.

FOSTER WALLACE, David. Conversations with David Foster Wallace (Stephen J. Burn ed.). University Press of Mississippi, 2012.

ISER, Wolfgang. O fictício e o imaginário: perspectivas de uma antropologia literária. Rio de Janeiro: EdUERJ, 2017.

JENSEN, Casper Bruun; KEMIKSIZ, Asli. Experiments in Thinking across Worlds. NatureCulture, v. 5, p. i-xiii, 2019.

KOPENAWA, Davi; ALBERT, Bruce. A queda do céu: Palavras de um xamã yanomami. São Paulo: Companhia das Letras, 2015.

LE GUIN, Ursula K. The Critics, the Monsters, and the Fantasists. The Wordsworth Circle, v. 38, n. 1-2, p. 83-87, 2007.

LÉVI-STRAUSS, Claude; ERIBON, Didier. De perto e de longe - entrevista com Claude Lévi-Strauss. Tradução de Julieta Leite e Léa Mello. São Paulo: Cosac Naify, 2005.

LIMA, Tania Stolze. O dois e seu múltiplo: reflexões sobre o perspectivismo em uma cosmologia tupi. MANA, v. 2, n. 2, 21-47, 1996.

LUDMER, Josefina. Aqui, América Latina. Belo Horizonte: Editora UFMG, 2013. 
MANIGLIER, Patrice. La Parenté des autres (à propos de Maurice Godelier: Métamorphoses de la parenté). Citique, n. 701, p. 758-74, 2005.

NAGEL, Thomas. Como é ser um morcego?. Tradução de Paulo Abrantes e Juliana Orione. Cad. Hist. Fil. Ci., Campinas, Série 3, v. 15, n. 1, p. 245-262, jan.-jun. 2005.

NODARI, Alexandre. "A vida oblíqua": o hetairismo ontológico segundo G.H. O Eixo e a roda, Belo Horizonte, v. 24, n. 1, p. 139-154, 2015 a.

NODARI, Alexandre. A literatura como antropologia especulativa. Revista da Anpoll n. 38, p. 75-85, Florianópolis, Jan./Jun. 2015 b.

NODARI, Alexandre. Quase-evento: sobre a estoricidade da experiência literária. eLyra: Revista da Rede Internacional Lyracompoetics, n. 10, 16 jan. 2017.

NUNES, Rodrigo. “A política no meio”. In: SIQUEIRA, Mauricio; COCCO Giuseppe (org.). Por uma política menor: arte, comum e multidão. Rio de Janeiro: Fundação Casa de Rui Barbosa, 2014.

PIGLIA, Ricardo. Las tres vanguardias - Saer, Puig, Walsh. Ciudad Autónoma de Buenos Aires: Eterna Cadencia, 2016.

QUILES, Carlos; LÓPEZ-MENCHERO Fernando. A grammar of Modern Indo-European. Sevilla: Academia Prisca, 2017.

RANCIÈRE, Jacques. O efeito de realidade e a política da ficção. Novos Estudos Cebrap, edição 86, v. 29, n. 1, p. 75-90, março de 2010.

SAER, Juan José. O conceito de ficção. Tradução de Luís Eduardo Wexell Machado. Revista FronteiraZ, São Paulo, n. 8, julho de 2012.

STENGERS, Isabelle. A proposição cosmopolítica. Tradução de Raquel Camargo e Stelio Marras. Revista do Instituto de Estudos Brasileiros, Brasil, n. 69, p. 442-464, abr. 2018.

STERZI, Eduardo. Hipóteses. Meteöro, São Paulo, v. 1, p. 249-257, 2019.

STIERLE, Karlheinz. A ficção. Tradução de Luiz Costa Lima, (orgs.) Carlinda Fragale Pate Nuñez, Francisco Venceslau dos Santos. Rio de Janeiro: Caetés, 2006.

THOMAS, Yan. Los artificios de las instituciones. Estudios de derecho romano. Tradução ao castelhano de Silvia de Billerbeck. Buenos Aires: Eudeba, 1999.

TOUAM BONA, Dénètem. Cosmopoéticas do refúgio. Desterro: Cultura e Barbárie, 2020.

UEXKÜLL, Jakob von. Andanzas por los mundos circundantes de los animales y los hombres. Ciudad Autónoma de Buenos Aires: Cactus, 2016. 
VALENTIM, Marco Antonio. Ursa menor: notas sobre ficção científica e fantasia. Cadernos pet-filosofia: Filosofia e literatura, n. 17, p. 9-35, 2018a. Disponível em:

https://revistas.ufpr.br/petfilo/article/view/65845/38022. Acesso em: 15 abr. 2020.

VALENTIM, Marco Antonio. Introdução à Xenologia. 2018b.

VIVEIROS DE CASTRO, Eduardo. O nativo relativo. Mana, Rio de Janeiro, v. 8, n. 1, p. 113-148, abr. 2002. Disponível em:

https://www.scielo.br/j/mana/a/ZcqxxhqhZk9936mxW5GRrhq/?lang=pt. Acesso

em: 15 abr. 2020.

VIVEIROS DE CASTRO, Eduardo (org.); SZTUTMAN; Renato (org.). Encontros: Eduardo Viveiros de Castro. Rio de Janeiro: Beco do Azougue, 2008.

VIVEIROS DE CASTRO, Eduardo. Metafísicas canibais. São Paulo: Cosac Naify: n-1 edições, 2015a.

VIVEIROS DE CASTRO, Eduardo. Who is afraid of the Ontological Wolf?. The Cambridge Journal of Anthropology, v. 33, n. 1, p. 2-17, Spring, 2015b.

VIVEIROS DE CASTRO, Eduardo. Eduardo Viveiros de Castro: 'O que se vê no Brasil hoje é uma ofensiva feroz contra os índios'. [Entrevista concedida a] Guilherme Freitas. O Globo, agosto, 2015c. Disponível em: https://oglobo.globo.com/cultura/livros/eduardo-viveiros-decastro-que-se-ve-no-brasil-hoje-uma-ofensiva-feroz-contra-os-indios-17261624. Acesso em: 15 abr. 2020.

VIVEIROS DE CASTRO, Eduardo. Metaphysics as Mythophysics. In: CHARBONNIER, Pierre; SALMON, Gildas; SKAFISH, Peter (org.): Comparative metaphysics: ontology after anthropology. Lanham: Rowman \& Littlefield International, 2017.

Artigo submetido em: 12 jul. 2021

Aceito para publicação em: 12 out. 2021

DOI: https://dx.doi.org/10.22456/2238-8915.116714 